\title{
REKAYASA PRODUKTIVITAS DENGAN PENDEKATAN GREEN ENGINEERING PADA PT. ABC
}

\author{
Sukaria Sinulingga ${ }^{1}$, A. Rahim Matondang ${ }^{1}$, Yusnia Sinambela ${ }^{2}$ \\ Program Magister Teknik Industri ${ }^{1}$, Alumni Program Magister Teknik Industri ${ }^{2}$ \\ Jl. Prof.T.Maas Kampus USU, Medan 20155 \\ Email: yusnia_snbl@yahoo.co.id \\ Email: sukaria_sinulingga@yahoo.com \\ Email: rahim@usu.ac.id
}

\begin{abstract}
Abstrak. PT.ABC merupakan perusahaan yang bergerak di bidang produksi pembuatan pintu. Dalam melakukan proses produksi perusahaan ini memiliki potensi untuk menghasilkan limbah. Permasalahan yang dialami perusahaan adalah banyaknya limbah padat berupa scrap kayu yaitu sebanyak $23 \%$ dari bahan baku setiap bulannya dan nilai produktivitasnya cendrung tidak stabil. Melalui pendekatan Green Engineering yang digunakan dalam penelitian ini diharapkan usaha reduksi limbah yang dilakukan dapat berpengaruh terhadap perbaikan kondisi lingkungan sekaligus meningkatkan produktivitas perusahaan. Penelitian diawali dengan mengidentifikasi sumber penyebab masalah, menentukan tujuan dan target, menyusun alternatif serta mengestimasi kontribusi alternatif terpilih terhadap produktivitas dan kinerja lingkungan. Alternatif perbaikan dirumuskan dan dipilih berdasarkan kelayakan dari segi ekonomi, segi lingkungan, dan segi social, kemudian dilakukan usulan perencanaan implementasi alternatif di dalam lokasi. Hasil penelitian, didapatkan alternatif solusi untuk mengatasi permasalahan perusahaan dengan melakukan rekayasa berbasis teknologi dan pemanfaatan kembali scrap kayu menjadi briket arang kayu. Alternatif ini memberikan kontribusi terhadap peningkatan produktivitas penggunaan material sebesar $17 \%$, manusia $24 \%$, modal $7 \%$, energi $25 \%$, pajak karbon menurun sebesar 53,29\% dan waste menurun sebesar 87,44\%. Penerapan Green Engineering dan pemantauan rona lingkungan secara keseluruhan dapat membantu perusahaan memenuhi salah satu persyaratan ISO 14001.
\end{abstract}

Kata Kunci: Green Productivity Index, Enviromental Performance, Limbah Padat, ISO 14001.

Abstract. PT.ABC is a company engaged in the production of the manufacture of doors. In the production process of this company has the potential to produce waste. The problems experienced by the company is the number of solid waste such as scrap wood as many as $23 \%$ of raw materials every month and the value of productivity tends to be unstable.Through the Green Engineering approaches used in this study are expected waste reduction efforts made can affect the improvement of environmental conditions and increase productivity begins. By identifying the source of the cause of the problem, setting objectives and targets, prepare alternatives and alternative contribution elected productivity and environmental performance. Alternative repair formulated and selected based on feasibility in terms of economy, in terms of the environment, and socially, then do the planning proposals alternative implementations within the premises. The results of the research, found an alternative solution to overcome problems with the company's engineering and technology-based reuse of scrap wood into charcoal briquettes. This alternative contributes to the increased productivity of material usage by $17 \%$, men $24 \%$, capital 7\%, energy 25\%, carbon tax decreased by $53.29 \%$ and waste decreased by $87.44 \%$. Green Engineering and environmental monitoring a whole can help companies meet one of the requirements of ISO 14001.

Keywords: Green Productivity Index, Environmental Performance, Solid Waste, ISO 14001. 


\section{PENDAHULUAN}

Produktivitas merupakan satu hal yang sangat penting bagi perusahaan sebagai salah satu cara untuk memantau kinerja produksinya. Pengukuran produktivitas dilakukan untuk mengetahui kinerja perusahaan secara keseluruhan serta dapat dijadikan sebagai pedoman untuk melakukan perbaikan yang terus-menerus (continual improvement). PT. ABC adalah suatu perusahaan manufaktur yang bergerak dalam bidang pembuatan pintu. Dalam melaksanakan produksinya, PT. ABC menggunakan kayu sebagai material utama. Seiring dengan peningkatan produksi, ternyata timbul permasalahan lingkungan di sekitarnya. Permasalahan tersebut disebabkan karena proses. Selama proses produksi, PT.ABC menghasilkan limbah cemaran di berbagai stasiun kerja terdiri atas limbah padat, limbah cair dan limbah udara. Limbah cair berasal dari pencucian mesin, dan pengeleman bahan dengan mal glue, untuk limbah gas berasal dari aktivitas motor hidrolik dan dapur boiler.

$$
\text { Hasil analisa dengan standar }
$$

PerMenkertrans No.13/MEN/X/2011 dan

Kep.MENLH/51/10/1996 bahwa kandungan zat-zat kimia dalam limbah cair dan limbah udara telah memenuhi baku mutu limbah yang telah ditetapkan dan aman bagi lingkungan. Dari pengamatan di lapangan, untuk limbah padat terdapat adanya scrap kayu di berbagai stasiun kerja. Rendemen pemanfaatan bahan baku selama proses produksi sampai dengan bahan jadi dan gambaran jumlah scrap/ $\mathrm{m}^{2}$ dapat dilihat pada Tabel 1.

Tabel 1. Rendemen Kayu Olahan Tahun 2014

\begin{tabular}{|c|c|c|c|}
\hline Bulan & $\begin{array}{c}\text { Rendemen } \\
(\mathbf{\%})\end{array}$ & $\begin{array}{c}\text { Scrap } \\
(\boldsymbol{\%})\end{array}$ & $\begin{array}{c}\text { Scrap } \\
\left(\mathbf{m}^{\mathbf{3}}\right)\end{array}$ \\
\hline Januari & 72 & 28 & 153,9145 \\
\hline Februari & 73 & 27 & 107,541 \\
\hline Maret & 74,6 & 25,4 & 97,4665 \\
\hline April & 75,07 & 24,95 & 98,8971 \\
\hline Mei & 74,6 & 25,4 & 111,4284 \\
\hline Juni & 75,48 & 24,52 & 42,7666 \\
\hline Juli & 75,33 & 24,67 & 139,3016 \\
\hline Agustus & 68 & 32 & 159,5201 \\
\hline September & 73 & 27 & 180,4582 \\
\hline Oktober & 70 & 30 & 149,3660 \\
\hline November & 70 & 30 & 180,6278 \\
\hline Desember & 68,22 & 31,78 & 122,3166 \\
\hline
\end{tabular}

Upaya yang dilakukan perusahaan dalam menangani Limbah padat tersebut dengan memanfaatkan $45 \%$ untuk pemanasan di dapur boiler, sebagian diberikan kepada yang membutuhkan, ditumpuk di sekitar pabrik, dan jika darurat di buang ke TPA (Tempat Pembuangan Akhir).

Dampak dari limbah padat tersebut jika ditimbun dan membusuk dapat menimbulkan penurunan kualitas udara dan kerusakan permukaan tanah dan jika limbah padat tersebut keberadaannya dalam jumlah yang besar tanpa dikelola, maka akan sulit bagi mikroba perombak untuk mengurainya di alam menjadi bahan-bahan anorganik,dan mengakibatkan pencemaran lingkungan di sekitar lokasi penumpukan. Selain menjadi sarang hewanhewan yang kemungkinan bisa menjadi sumber penyakit, tumpukan sampah padat kayu tersebut akan menurunkan nilai estetika di lokasi sekitar. Jika limbah padat dibakar maka akan menimbulkan peningkatan emisi $\mathrm{CO}_{2}$ (Anonim,2000).

Pada saat ini kayu adalah bahan yang cukup sulit diperoleh maka diperlukan efisiensi penggunaan bahan kayu. Jika dilakukan pemanfaatan scrap dari terhadap estimasi produk diatas, maka estimasi jumlah pintu yang dihasilkan dapat dilihat pada Tabel 2.

Tabel 2. Estimasi Jumlah Produk dari Scrap

\begin{tabular}{|c|c|c|}
\hline Bulan & Scrap $\left.\mathbf{( m}^{\mathbf{3}}\right)$ & $\begin{array}{c}\text { Estimasi Jumlah } \\
\text { Produk dari } \\
\text { Scrap } \text { (Pintu) }\end{array}$ \\
\hline Januari & 153,9145 & 3078 \\
\hline Februari & 107,541 & 2151 \\
\hline Maret & 97,4665 & 1949 \\
\hline April & 98,8971 & 1978 \\
\hline Mei & 111,4284 & 2229 \\
\hline Juni & 42,7666 & 855 \\
\hline Juli & 139,3016 & 2786 \\
\hline Agustus & 159,5201 & 3190 \\
\hline September & 180,4582 & 3609 \\
\hline Oktober & 149,3660 & 2987 \\
\hline November & 180,6278 & 3613 \\
\hline Desember & 122,3166 & 2446 \\
\hline
\end{tabular}

Pemanfaatan jumlah scrap tersebut akan membantu perusahaan dalam meningkatkan produktivitas perusahaan. Permasalahan perusahaan tersebut memerlukan solusi dan alternatif usulan perbaikan. Suatu pendekatan yang tepat untuk membantu perusahaan agar mampu meningkatkan produktivitas sekaligus menurunkan dampak lingkungan adalah dengan menggunakan metode Green Engineering.

\section{METODOLOGI PENELITIAN}

\subsection{Tempat dan Waktu Penelitian}

Penelitian ini dilakukan di PT. ABC yang bergerak dalam bidang produksi pembuatan pintu. 
Perusahaan berlokasi Penelitian beralamat di Jl. Batang Kuis, Km 2 Desa Buntu Bedimbar Tanjung Morawa Sumatera Utara. Waktu penelitian dilakukan pada bulan April 2015.

\subsection{Jenis dan Objek Penelitian}

Jenis penelitian yang dilakukan adalah penelitian tindakan (action research) yaitu suatu penelitian yang dilakukan untuk mendapatkan temuan praktis untuk keperluan operasional (Sinulingga, 2013). Penelitian ini bertujuan untuk mendapatkan suatu solusi yang akan digunakan pada perusahaan sebagai bentuk perbaikan dari sistem semula. Objek penelitian yang diamati adalah proses produksi yang terjadi pada bagian produksi PT. $\mathrm{ABC}$.

\subsection{Desain Penelitian}

Sumber data yang digunakan dalam penelitian adalah data primer dan data sekunder. Data primer diperoleh dengan cara pengamatan atau pengukuran langsung. Data yang termasuk kategori ini adalah:

a. Data environment weather map

b. Data daerah penumpukan waste

c. Data penilaian skor untuk waste

Data sekunder diperoleh berdasarkan data dokumentasi perusahaan. Data yang termasuk kategori ini adalah:

a. Data penggunaan jenis kayu

b. Data jenis pintu

c. Data penggunaan bahan

d. Data biaya dan harga

e. Data kandungan energi

Selain itu, metode pengumpulan data dilakukan dengan melakukan wawancara atau tanya jawab dengan penanggung jawab bagian produksi mengenai hal-hal yang berhubungan dengan penelitian dan mengumpulkan data sekunder yang diambil dari dokumen-dokumen perusahaan yang berhubungan dengan penelitian.

\subsection{Tahapan Penelitian.}

Langkah-langkah metode Green Engineering adalah sebagai berikut:

a. Perhitungan Produktivitas.

b. Identifikasi Masalah dan Penyebabnya.

Identifikasi masalah dilakukan dengan studi lapangan (walk trough survey),sedangkan identifikasi penyebabnya menggunakan tool diagram sebab akibat (cause effect diagram).

c. Menentukan Tujuan dan Target.

Identifikasi masalah dan penyebab timbulnya waste,selanjutnya dapat ditentukan tujuan dan target penelitian yang ingin dicapai yaitu meminimalisir waste dan meningkatkan produktivitas perusahaan dengan metode Green Engineering.

d. Menyusun Alternatif Solusi.

Pada tahap ini dikembangkan beberapa alternatif solusi untuk menyelesaikan permasalahan yang ada, tujuannya untuk mengoptimalkan penggunaan input (material, tenaga kerja, energi). Pada tahap ini alternatif yang dibuat harus memiliki aspek ramah lingkungan, meminimalisir timbulnya waste selama produksi serta dapat meningkatkan produktivitas perusahaan.

e. Memilih Alternatif Solusi.

Terdapat hal yang menjadi dasar pertimbangan pemilihan alternatif solusi yaitu:

1. Analisis finansial dari tiap alternatif solusi yang telah dibuat dengan metode Deret Seragam (Annual Worth).

2. Estimasi kontribusi tiap alternatif terhadap tingkat produktivitas.

3. Estimasi kontribusi tiap alternatif terhadap waste.

4. Estimasi Kontribusi Tiap Alternatif Terhadap Pendapatan Masyarakat

5. Estimasi Kontribusi Tiap Alternatif Terhadap Pertimbangan Emisi Karbon.

f. Menyusun Rencana Implementasi.

Setelah didapatkan alternatif solusi perbaikan yang memiliki kontribusi terbesar terhadap peningkatan produktivitas dan pengurangan waste selanjutnya dilakukan penyusunan rencana implementasi dari alternatif solusi yang terpilih. Pada tahap ini dilakukan perencanaan tindakantindakan yang akan dilakukan pihak pelaksana solusi yang terpilih serta sumber daya yang akan digunakan.

g. Melakukan Pemantauan dan Evaluasi Alternatif Solusi terpilih maka dilakukan pemantauan dan evaluasi dengan analisis IRR (Internal Rate Return) selama periode tertentu.

h. Analisis mendapatkan Sertifikasi ISO 14001.

Pada tahapan ini alternatif solusi diintergrasikan menjadi bagian dalam manajemen harian.

\section{HASIL DAN PEMBAHASAN}

\subsection{Perhitungan Produktivitas}

Produktivitas diperoleh dengan membandingkan antara output dan input. Nilai input didapatkan dari penjumlahan biaya bahan baku, biaya tenaga kerja, biaya energi, biaya modal yang dikeluarkan selama proses produksi dalam satu tahun. Gambaran Nilai Produktivitas Perusahaan tahun 2014 dapat dilihat pada Gambar 1. 


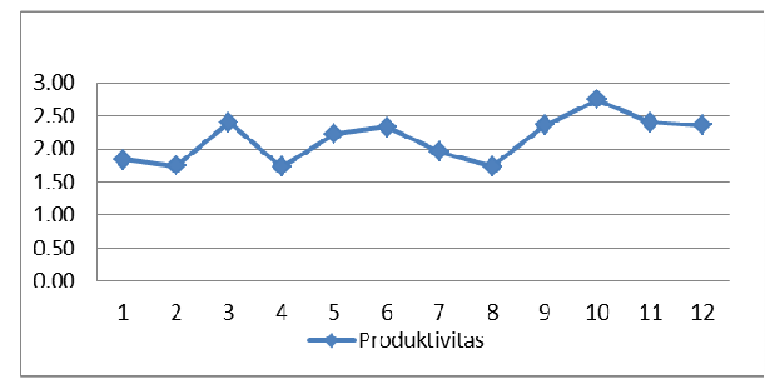

Gambar 1. Grafik Produktivitas Bulan Januari Desember 2014

Berdasarkan Gambar 1 di atas dapat dilihat bahwa nilai produktivitas menunjukkan ketidakstabilan. Pada bulan Februari dan April mengalami penurunan dan mulai mengalami peningkatan di bulan mei, bulan Agustus sampai bulan Oktober dan bulan November sampai Desember kembali mengalami penurunan.

\subsection{Identifikasi Masalah}

Identifikasi masalah dilakukan dengan analisa $5 \mathrm{~W}+1 \mathrm{H}$, untuk mengetahui permasalahan limbah yang paling dominan. Permasalahan yang terjadi diidentifikasi penyebabnya menggunakan cause effect diagram dapat dilihat pada Gambar 2 dapat dijelaskan faktor-faktor penyebab terjadinya limbah padat selama proses produksi karena beberapa faktor berikut:

a. Material

Material yang digunakan pada saat proses pembelian bahan baku dari supplier tidak ada ketentuan ukuran dan proses pemeriksaan adanya bahan yang tidak sesuai kualitas seperti kayu basah. retak dan berjamur. Hal ini menjadi penyebab timbulnya waste.

b. Mesin

Proses pembuatan pintu dari awal pembuatan hingga akhir membutuhkan pengukuran dan mengikuti ukuran yang sudah ditetapkan. Mesin yang digunakan PT.ABC $80 \%$ mesin semiotomatis. mesin-mesin tersebut tidak memiliki ukuran sehingga pada saat pengukuran bahan baku dilakukan secara manual dengan alat ukur seperti meteran. Mesin yang digunakan juga performanya menurun disebabkan karena mesin sudah lama. sehingga efisiensi proses tidak optimal.

c. Man

Dalam pembuatan pintu ada batas toleransi yang harus di ikuti oleh operator. Misalnya pada proses pemilihan bahan. toleransi yang diterima panjang $\pm 2 \mathrm{~mm}$. Lebar $\pm 2 \mathrm{~mm}$. Tebal $\pm 0.01 \mathrm{~mm}$. Diluar batas toleransi tersebut tidak dapat dipergunakan (reject) maka menghasilkan scrap. Karyawan harus dengan teliti dalam mengukur dan bagian Quality Control juga harus memberikan informasi dengan jelas kepada Operator.

d. Environment

Bahan baku disimpan di ruang yang luas dan tidak adanya kontrol ventilasi dan aliran udara. Jika bahan baku kelembabannya tinggi akan merusak kayu tersebut. Hal tersebut mengakibatkan limbah kayu.

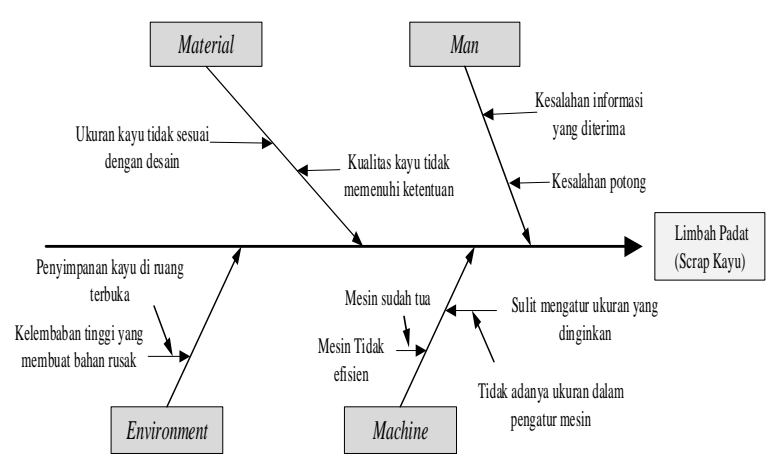

Gambar 2. Cause Effect Diagram

\subsection{Menentukan Tujuan dan Target}

Berdasarkan identifikasi masalah, maka masalah target yang ingin dicapai yaitu mereduksi scrap kayu pada bagian produksi dengan melakukan reduksi tersebut akan meningkatkan produktivitas perusahaan dan menurunkan dampak negatif scrap terhadap lingkungan.

\subsection{Menyusun Alternatif Solusi}

Dari permasalahan yang timbul akibat volume limbah padat, maka disusun alternatif solusi yang dapat memperbaiki hal tersebut. Tiga alternatif perbaikan yang telah disusun, akan dipilih satu alternatif solusi nantinya akan digunakan sebagai rencana implementasi. Adapun alternatif tersebut adalah:

1. Sebagai pembanding maka kondisi sekarang diusulkan sebagai alternatif.

2. Dilakukan pembelian mesin $\mathrm{CNC}$ untuk mengurangi scrap kayu di bagian pemotongan. Berdasarkan hierarki pencegahan polusi dengan reuse (material digunakan kembali dalam proses produksi). Scrap kayu berupa sisa potongan. sisa gergajian dapat di proses menjadi serbuk kayu. Serbuk kayu tersebut dipress dan dapat dimanfaatkan sebagai partical board yang merupakan bahan tambahan pembuatan pintu. Perusahaan dalam memenuhi bahan tambahan tersebut membeli dari perusahaan produksi Partical Board. Untuk dapat memenuhi alternatif ini. 
diperlukan:Mesin wood crusher sebagai alat penghancur dan mesin press untuk membentuk hasil olahan serbuk. Pengganti bahan bakar pada proses pemanasan yaitu menggantikan energi pemanasan di boiler yang cukup ekonomis dengan cangkang kelapa sawit. Emisi $\mathrm{CO}_{2}$ cangkang sawit lebih kecil dibandingkan Scrap kayu.

3. Alternatif dengan recycle memungkinkan untuk dilakukan dengan memanfaatkan limbah serbuk kayu untuk dijadikan bahan baku briket arang. Scrap kayu berupa sisa potongan. sisa gergajian dapat di proses menjadi serbuk kayu dan diperlukan mesin wood crusher sebagai alat penghancur. Untuk dapat memenuhi alternatif ini. diperlukan mesin wood crusher dan mesin yang mendukung pembuatan briket. Briket arang akan dimanfaatkan untuk pemanasan di dapur boiler. Briket kayu memiliki nilai kalor yang lebih besar dari scrap kayu $(79 \%)$ dan Emisi $\mathrm{CO}_{2}$ lebih rendah dari pemanfaatan scrap kayu. Menggunakan Rekayasa berbasis Teknologi dengan Maintenance Management. Mesin yang efisien mengurangi timbulnya scrap kayu misalnya ketika campuran bahan jadi dimasukkan ke dalam mesin. terdapat campuran bahan jadi yang tidak mengalami proses pengangkatan dan dihisap oleh pipa penghisap untuk di bawa ke proses selanjutnya.

\subsection{Memilih Alternatif Solusi}

Pemilihan Alternatif solusi pada penelitian ini berdasarkan beberapa hal yang menjadi bahan pertimbangan yaitu estimasi alternatif terhadap produktivitas, estimasi waste, Pertimbangan Emisi Karbon, Pendapatan Masyarakat dan Aspek Finansial dengan metode deret seragam. Kontribusi setiap Alternatif dapat dilihat pada Tabel 3. Berdasarkan Tabel 3 di bawah ini, maka akan membantu peneliti dalam memilih alternatif solusi perbaikan yang memperhatikan aspek lingkungan, aspek sosial dan aspek ekonomi.

Dari bahan pertimbangan tersebut maka dipilih Alternatif 3 adalah alternatif yang dipilih untuk diimplementasikan sebagai solusi perbaikan karena memiliki kontribusi yang besar terhadap kinerja produktivitas perusahaan dan kinerja lingkungan.

\subsection{Menyusun Rencana Implementasi}

Setelah didapatkan alternatif solusi perbaikan yang memiliki kontribusi terbesar terhadap peningkatan produktivitas dan kinerja lingkungan, maka berikutnya dilakukan penyusunan rancangan implementasi dari alternatif yang telah terpilih tersebut yaitu alternatif 3 .

Tabel 3. Kontribusi Alternatif

\begin{tabular}{|c|c|c|}
\hline Pertimbangan & $\begin{array}{r}\text { Kontribusi } \\
\text { Alternatif } 2\end{array}$ & $\begin{array}{c}\text { Kontribusi } \\
\text { Alternatif } \\
\mathbf{3}\end{array}$ \\
\hline \multicolumn{3}{|l|}{ Produktivitas } \\
\hline Human & $9 \%$ & $24 \%$ \\
\hline Material & $25 \%$ & $7 \%$ \\
\hline Modal & $10 \%$ & $7 \%$ \\
\hline Energy & $24 \%$ & $25 \%$ \\
\hline Waste & $-85.71 \%$ & $-87.44 \%$ \\
\hline Emisi Karbon & $-27.68 \%$ & $-53.33 \%$ \\
\hline $\begin{array}{l}\text { Biaya Kerusakan } \\
\text { Lingkungan }\end{array}$ & $-27.92 \%$ & $-53.29 \%$ \\
\hline $\begin{array}{l}\text { Aspek Pendapatan } \\
\text { masyarakat }\end{array}$ & $1.66 \%$ & $2 \%$ \\
\hline Indeks BCR & 2.85 & 4.51 \\
\hline
\end{tabular}

Dalam menerapkan alternatif/usulan dilantai pabrik produksi diperlukan beberapa urutan pekerjaan yaitu Trial and small scale implementation, Regular meetings and trouble shooting session, Follow-up and accountability, Allocate resources, Management support needed, Review and refinement of option, dan Capture information "before" and "after" implemented option.

\subsection{Melakukan Pemantauan dan Evaluasi}

Setelah dilakukan usulan implementasi alternatif 3, maka dilakukan monitoring and review dengan melakukan analisi IRR selama periode 5 tahun kedepan. Untuk perhitungan basic data maka asumsi yang diperlukan yaitu Pajak 20\%, Commision Fee 5\%, biaya tenaga kerja diperkirakan meningkat $15 \%$, biaya energi $10 \%$. Hasil perhitungan NPV pada tingkat suku bunga $26 \%$ menunjukkan nilai negatif, sedangkan pada tingkat suku bunga $25 \%$ menunjukkan nilai positif sehingga IRR berada antara $25 \%$ dan $26 \%$. Besarnya nilai IRR yaitu $25,31 \%$. Hasil perhitungan IRR menunjukkan bahwa tingkat pengembalian dari perusahaRekayasa Produktivitas dengan Pendekatan Green Engineering pada PT.Sumatera Timberindo Industry.an ini lebih tinggi dibanding tingkat suku bunga bank yaitu $18 \%$ sehingga dapat dikatakan usaha ini layak. Nilai IRR jauh lebih tinggi menunjukkan bahwa pengembalian perusahaan ini masih jauh lebih baik.

\subsection{Analisis mendapatkan Sertifikasi ISO 14001.}

Penerapan Green Engineering pada Perusahaan dapat memenuhi salah satu syarat Sertifikasi ISO 14001 yaitu memperhatikan kinerja lingkungan. 


\section{KESIMPULAN}

1. Persentase penurunan jumlah scrap dengan efektif adalah dengan mengimplementasikan alternatif ketiga, dimana diusulkan adanya tambahan mesin wood crusher dan mesin lainnya untuk mengolah scrap yang ada di pabrik menjadi briket arang kayu dan melakukan maintenance management. Dengan demikian, penggunaan kayu menjadi lebih efektif. Pengadaan mesin-mesin pendukung pembuatan briket tidak memerlukan tambahan luas lahan karena dapat ditempatkan di ruangan yang ada.

2. Penerapan atau implementasi dari alternatif perbaikan yang dipilih dengan melakukan urutan pengerjaan dan sosialisasi maka diestimasikan mampu memberikan kontribusi peningkatan produktivitas serta mampu memberikan kontribusi terhadap perbaikan kualitas atau kinerja lingkungan.

3. Perusahaan sudah memenuhi salah satu syarat Sertifikasi ISO 14001 karena sudah memperhatikan kinerja lingkungan.

\section{DAFTAR PUSTAKA}

Asian Productivity Organization. 2006. Handbook on Green Productivity. Canada.

David T.Allen.2012. Green Engineering: Environmantaly Conscius,Design of Chemical Process and Products. AICHE Journal.

Dian Anggraini. 2011. Upaya Pengelolaan Limbah Industri PT TEL Pulp and Paper. Jurnal Internet.

Ginting, Rosnani. 2007. Sistem Produksi. Yogyakarta: Graha Ilmu.

Graedel, Thomas E. dan Jennifer A. HowardGrenville. 2004. Greening the Industrial Facility. USA: Springer.

Heinz Werner Engel. 2002. Ecomapping. International Network for Environmental Management (INEM).

Indri, Cyrilla.2015. Evaluasi Produktivitas dan Kinerja Lingkungan Industri Tahu melalui Pengukuran EPI. Jurnal Nasional IENACO.2015.issn 2337-4349.

Jilla Decena. 2009. Green Productivity Initiatives: Intel Malaysia's Experience and Perspectives. Corporate Social Responsibility in Asia.

K.D.Bhardwaj. Green Productivitty and Sustainable Wate Management in the Asia-Pasific Region to Promote Eco Town Model. Industry Department:APO
Kementerian Negara Lingkungan Hidup Republik Indonesia. 2009. Emisi Gas Rumah Kaca dalam Angka.

Khane, Abd-El Rahman. TT. Manual for the Preparation of Industrial Feasibility Studies. UNIDO.

Ridiawan, Hari dan I Made Purna. 1991. Dampak Pariwisata Terhadap Masyarakat Sekitarnya. Direktorat Jenderal Kebudayaan. Jurnal Internet.

Singgih, Moses L, Mokh Suef, dan Chandra Adi Putra. 2010. Waste Reduction with Green Productivity Approach for Increasing Productivity. Jurnal Internet.

Singgih, Moses L. 2011. Penerapan Green Productivity pada Pabrik Pengolahan dan Pendinginan Ikan. Jurnal Internet.

Sutalaksana, Iftikar Z, Ruhana Anggawisastra, dan Jann H. Tjakraatmadja. 1979. Teknik Tata Cara Kerja. Bandung: ITB.

Santono, Haryi dan Puji Nugroho. 2015. Penerapan Green Productivity untuk Meningkatkan Productivitas dan kinerja Lingkungan di Pabrik gula Sragi. Jurnal Nasional IENACO 2015. Issn:2337-4349.

Widuri, Endang.2015. Analisis Produktivitas Proses Penyepuhan dengan Menggunakan Metode Green Productivity. Jurnal Nasional IENACO 2015. Issn : 2337-4349. 